Scientific Review - Engineering and Environmental Sciences (2019), 28 (4), 610-618

Sci. Rev. Eng. Env. Sci. (2019), 28 (4)

Przegląd Naukowy - Inżynieria i Kształtowanie Środowiska (2019), 28 (4), 610-618

Prz. Nauk. Inż. Kszt. Środ. (2019), 28 (4)

http://iks.pn.sggw.pl

DOI 10.22630/PNIKS.2019.28.4.55

Shahad R. Al-GHRYBAWI ${ }^{1}$, Monim H. Al-JIBOORI ${ }^{2}$

${ }^{1}$ College of Science, Mustansiriyah University

${ }^{2} \mathrm{MSc}$ student at the College of Science, Mustansiriyah University

\title{
Study of surface heat inversions characteristics around Baghdad station
}

Key words: heat inversion, frequency, relative frequencies, inversion height

\section{Introduction}

Increase of temperature with height in the troposphere is called temperature inversion (Kahl, Serreze \& Schnell, 1992; Li et al., 2015). Inversion is the reflection at the air temperatures of the natural air layers. Ideally warm air rises while the cold air comes down, causing the air around us to mix and move. This process is called convection, in which the temperature decreases with elevation. Air temperature inversion is one of the most important meteorological phenomena, in which atmospheric lapse rate is inverted i.e. air temperature increases with height instead of decreasing (Yasmeen, 2011).

During the night the ground loses heat and the low-level air cools this results in air temperature increasing with height and the temperature profile is said to be inverted. When this occurs close to the ground it is called a surface heat inversion (Al-Jiboori, 2015). Conditions that favour the development of a strong surface inversion are calm winds, clear skies, and long nights. Calm winds prevent warmer air above the surface from mixing down to the ground, and clear skies increase the rate of cooling at the earth's surface. Long nights allow for the cooling of the ground to continue over a longer period of time, resulting in a greater temperature decrease at the surface (Davidson \& Spink, 2018). Many of the climatological inversions are restricted to the surface heat inversions or the first elevated inversions (Tyson, Preston-Whyte \& Diab, 1976). The first stable layer, an inversion layer, encountered in a temperature profile is in many cases, and is important as it plays a central role in controlling air pollution dispersion (Milionis \& Davies, 1992).

Pollutants spread in the stable atmosphere throughout the heat inversion 
downward since the pollutants reflect from the top of the thermal inversion towards the earth's surface, where the top of the inversion limits the movement of the pollutants to stop the spread towards up (Zhang \& Li, 2011). Concentration of key air pollutants depends strongly upon the stability conditions in the lower atmosphere. Heat inversions, inversion layer height, and atmospheric stability, are probably the most important meteorological conditions controlling atmospheric pollution dispersion (Heidorn, 1978). Air temperature inversions are a common feature of pollution episodes around the world (Malek, Davis, Martin \& Silva, 2006). Several studies on the effect of atmospheric conditions on air pollution related air pollution episodes with heat inversions (Janhäll, Olofson, Andersson, Pettersson \& Halloquist, 2006).

Many studies have emphasized on the surface heat inversion for example Guédjé, Houéto and Houngninnou (2017) using daily (midnight and midday) upper-air meteorological data, found highest frequencies of elevated inversions was found in summer months whereas the peak of surface-based was in winter (Guédjé, Houéto \& Houngninnou, 2017). The aim of this work focuses on studying the frequency of heat inversions near to the earth's surface and variation of the heat inversions height in Baghdad for the period 2013-2014.

\section{Site and data}

Weather station is located at the International Baghdad Airport with geographical coordinates: latitude $33.14^{\circ} \mathrm{N}$ and longitude $43.34^{\circ}$ E. The elevation of the station is at $33 \mathrm{~m}$ above mean sea level. This station is located in a suburb about $16 \mathrm{~km}$ west of downtown Baghdad in the Baghdad governorate (Al-Jiboori \& Jaber, 2018).

For the purpose of studying this research were obtained radiosonde data, which include the temperature and elevation of the Baghdad station belonged to Iraqi Meteorological Organization and Seismology (IMOS) for a period of one year (2013-2014). The station is supposed to give the observations two times a day (00:00 and 12:00 GMT), but unfortunately it is available only one time (00 GMT). Data have been provided to us in the form of variable levels and has been processed and tabulated on a daily basis for the purpose of this work on this model. The data contains air temperature, pressure, height, dew temperature, humidity and wind speed with its direction. They saved in a CD.

\section{Methodology}

Using MATLAB software the air temperature profile was plotted for all the data used for the study the surface inversion profiles were selected to execute this work one of the air temperature distribution profiles with the height of each day in which a surface heat inversion occurred to illustrate and understand what happens during the heat inversion as in Figure 1.

Surface heat inversion cases were tested for the purpose of calculating frequencies of inversions close to the earth's surface in two ways: 


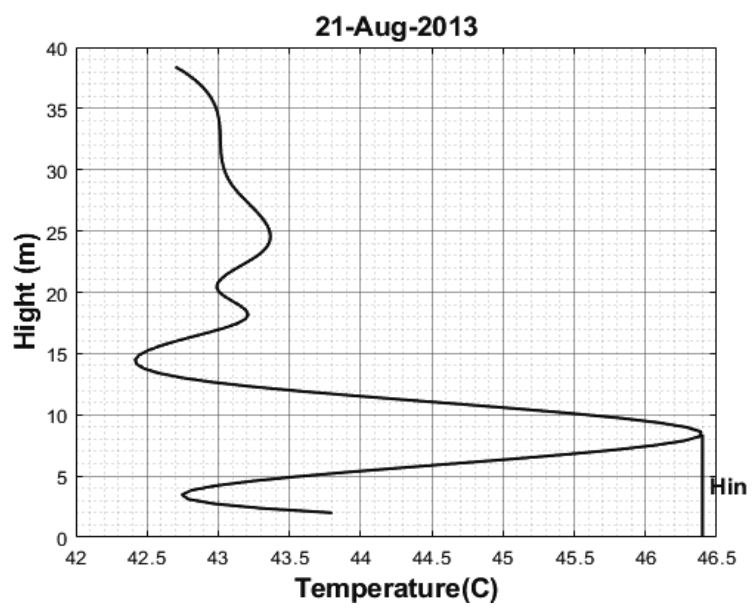

FIGURE 1. Air temperature profile of Baghdad for 21 August 2013

a) A relative frequencies $(R F)$ of the monthly and seasonal surface heat inversions where the relative frequency of the inversions for a given month represents the number of inversion cases for that month divided by the number of days of the month multiplied by one. The relative frequency of the inversions of a particular season represent the number of inversion for that season divided by the total number of days during each season multiplied by 100 as given:

$R F=N_{\text {in }} / N_{T} \cdot 100$

where:

$N_{\text {in }}$ - number of surface heat inversion cases;

$N_{T}$ - total number of month or season.

b) Frequency average of monthly and quarterly heat inversions where the frequency of inversion for a given month represents the number of inversion cases for that month divided by the number of days of the month. The frequency average $(F A)$ of in- versions for a particular season represents the number of inversion for that season divided by the number of days of separation as shown in equation (1) but without multiplying by 100:

$$
F A=N_{\text {in }} / N_{T}
$$

The height of the inversion layer represents the high end of the inversion layer from its base at which the highest air temperature is and then, it was calculated on a quarterly basis starting from the winter.

\section{Results and discussion}

\section{Frequencies of surface heat inversions}

The focus was on studying of the frequencies of heat inversions near the earth's surface. Relative frequencies of the monthly inversions near the earth's surface were calculated. The results of $R F$ are highest in September with percentage of $70 \%$, while the lowest is in the March and October with percentage of $19 \%$. As shown in Table 1, which 
TABLE 1. Number of monthly surface heat inversions cases

\begin{tabular}{|l|c|c|}
\hline Month & $\begin{array}{c}\text { Number } \\
\text { of inversion }\end{array}$ & $\begin{array}{c}R F \\
(\%)\end{array}$ \\
\hline January & 11 & 35 \\
\hline February & 17 & 61 \\
\hline March & 6 & 19 \\
\hline April & 14 & 47 \\
\hline May & 13 & 42 \\
\hline June & 14 & 47 \\
\hline July & 18 & 58 \\
\hline August & 14 & 45 \\
\hline September & 21 & 70 \\
\hline October & 6 & 19 \\
\hline November & 9 & 30 \\
\hline December & 16 & 52 \\
\hline Sum & 159 & 44 \\
\hline
\end{tabular}

shows the percentages of frequencies of low-level inversions per month during the year studied.

However, the relative frequencies of relative surface inversions were calculated and the results were the winter and
TABLE 2. Number of seasonal surface heat inversions cases

\begin{tabular}{|l|c|c|}
\hline Season & $\begin{array}{c}\text { Number } \\
\text { of inversion }\end{array}$ & $\begin{array}{l}R F \\
(\%)\end{array}$ \\
\hline Winter & 44 & 49 \\
\hline Spring & 34 & 37 \\
\hline Summer & 45 & 49 \\
\hline Autumn & 36 & 40 \\
\hline
\end{tabular}

summer recorders the highest frequency of inversions (49\%), while the lowest frequency was in the spring $(37 \%)$, frequencies of surface inversions occurring during the seasons of the year are reported in Table 2, which shows the percentage of frequency of surface heat inversion per season, more frequencies are at winter and summer.

The monthly and seasonal frequencies average of inversions was calculated and using equation (1) and Figure 2, which shows the monthly frequency of the years taken for study starting from the January and the results were that the frequency was the highest value for it in

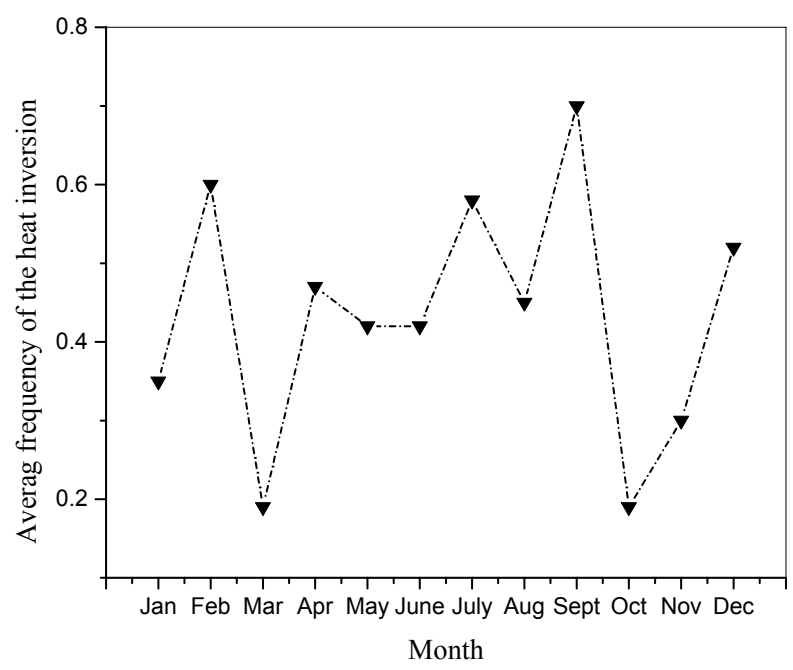

FIGURE 2. Frequency of monthly surface heat inversions 
September with value 0.7 and the lowest value of 0.19 is in March.

As for the rate of recurrences of the surface inversion of a particular season and the results are plotted as in Figure 3 which shows a change in the frequencies average of inversions per season and was the highest value for $A F$ in the summer and winter where the values were almost equal the summer and winter comes at the first rate and the average is 0.49 , followed the autumn it was the average is 0.4 and the lowest frequencies average of surface inversions in the spring, which is 0.37 . of inversions near the surface, which is the quiet winds where the warm air prevents the surface from mixing at the low of the earth, a clear sky that increases the cooling rate on the earth's surface and the long nights that continue to cool the earth over a longer period of time, resulting in a lower temperature on the surface and the inversion occur. Spring season is characterized by low average frequency because it is a transitional seasons characterized by sudden change in the atmosphere that causes the reduction of recurrence of the inversion. The

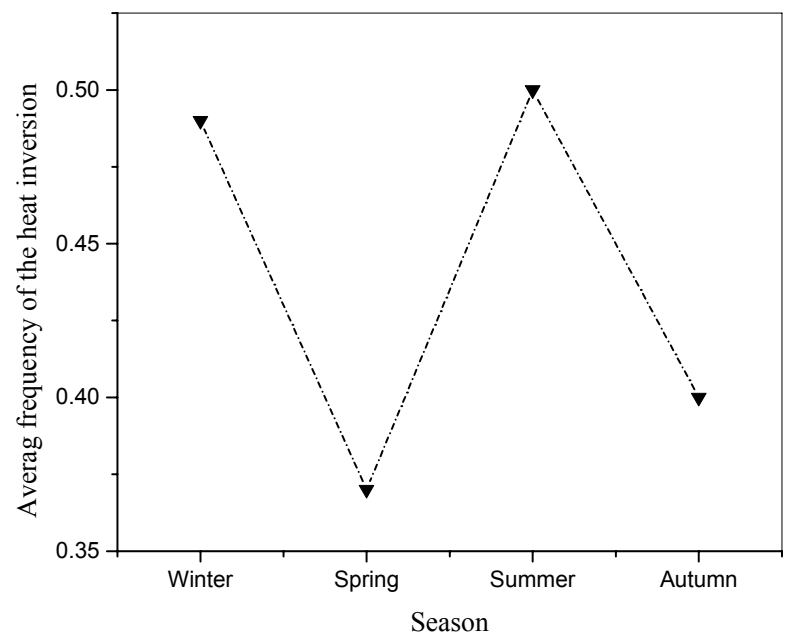

FIGURE 3. Frequency of seasonal surface heat inversions

The high frequencies average in the summer can be explained to the fact that it is during the summer, a very hot day follows a cold-night night where the sky free of clouds and low relative humidity to the increase in the rates of ground radiation and cooling of air near the surface of the earth, which helps to form inversion and can be applied to the autumn.

In the winter, there are geological conditions that increase the incidence increase in average frequency inversions in the autumn compared with the spring is due to the large decrease in the amount of clouds and wind speed.

\section{Surface inversion height}

Surface heat inversion cases were one of the surface heat inversion characteristics is its height which calculates as the height of the inversion layer on the surface up to a height where the air tem- 
perature decreases with height. The inversion layer height represents the high end of the inversion layer of its base. In general, height of the surface heat inversion $\left(H_{\text {in }}\right)$ may follow the general expression give as:

$H_{\text {in }}=a+b \cdot t+c \cdot t^{2}[\mathrm{~m}]$

where:

$a, b, c$-empirical constants derived from data of height and dates;

$t$ - number of date.

Equation (3) becomes linear if $c=0$. The values of these constants are derived for each season and reported in Table 3. Figures 4 shows the variations in the height of the layer of surface heat inversion during the winter that the highest

TABLE 3. The values of empirical constants for seasons

\begin{tabular}{|l|c|c|c|}
\hline Season & $\mathrm{a}$ & $\mathrm{b}$ & $\mathrm{c}$ \\
\hline Winter & 40.4 & 0 & - \\
\hline Spring & 35.1 & 0.04 & - \\
\hline Summer & -114.6 & 1.9 & -0.006 \\
\hline Autumn & - & - & - \\
\hline
\end{tabular}

rise in the winter is $50.5 \mathrm{~m}$. The results of inversion heights in winter shows approximately a constant behaviour during this season with a value of about $41 \mathrm{~m}$.

Figures 5 represents the change in the height of the surface heat inversion during spring, the highest rise of the base of the inversion in the spring was $51.9 \mathrm{~m}$. The results of inversion heights in spring shows linear behaviour during this season with a value of about $37 \mathrm{~m}$. In summer, the results of inversion heights have different behaviour from other seasons where non-linear behaviour is obvious. Figures 6 shows the change in the height of the surface heat inversion during the summer and the highest rise in the summer is $55.8 \mathrm{~m}$. Figures 7 shows the distribution of the height of the surface inversion during autumn. The highest altitude in the autumn was $52.6 \mathrm{~m}$, fitting during this season because it shows owing to the high scatter of $H_{\text {in }}$ values, the line fitting could not draw. The reason may be caused by receiving a different amounts solar radiation energy during this season.

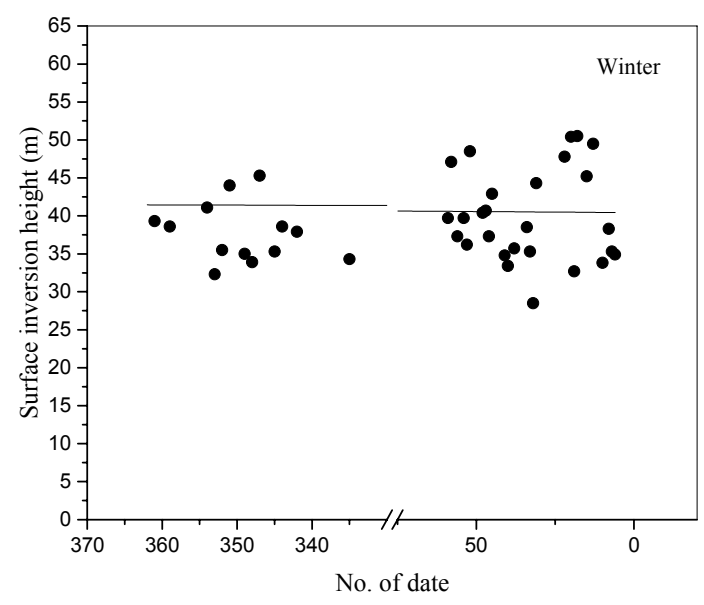

FIGURE 4. Daily variation in the height of the inversion during in the winter 


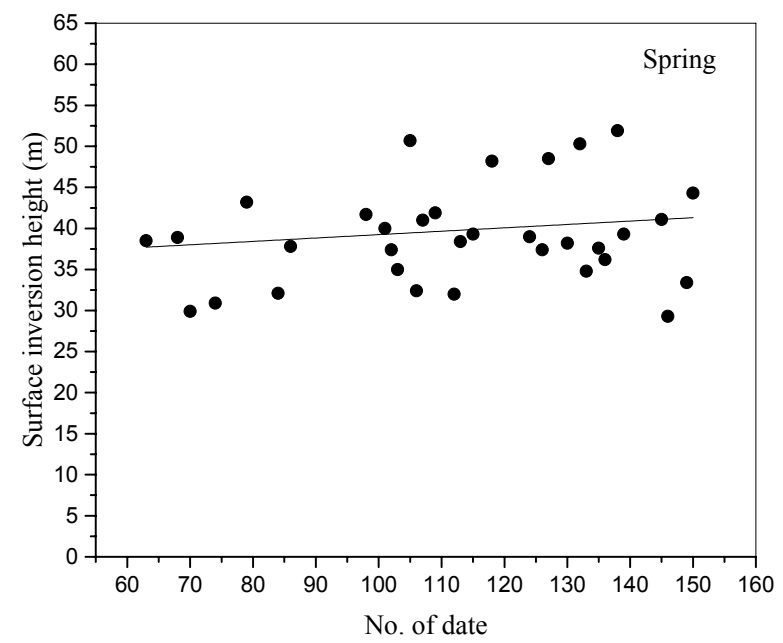

FIGURE 5. Daily variation in the height of the inversion during in the spring

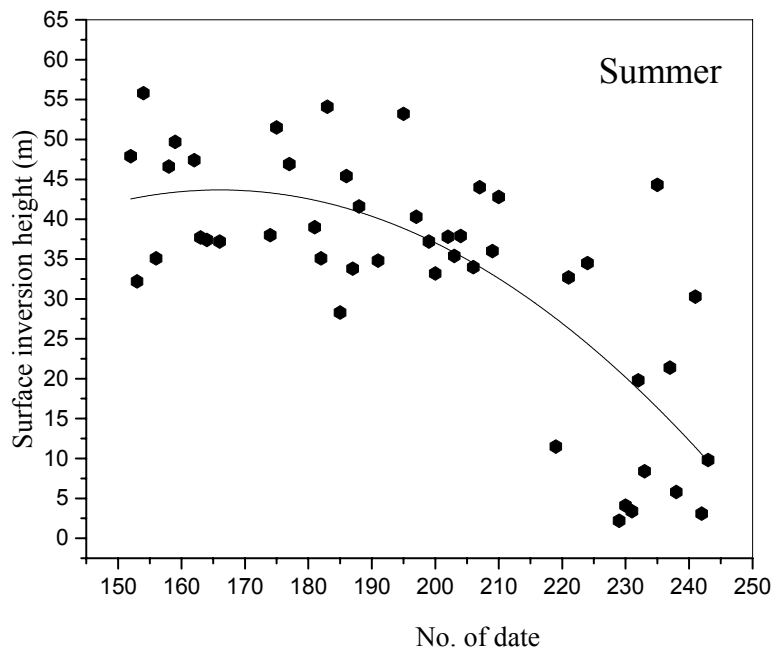

FIGURE 6. Daily variation in the height of the inversion during in the summer

After a comparison among the seasons, the results showed that the highest value for the rise of the surface layer of the surface heat transfer was in the summer where it was $55.8 \mathrm{~m}$ as shown in Figure 7 and that the lowest value was in the winter season which is $50.5 \mathrm{~m}$ as shown in Figure 5. The reason for this is due to the air temperature differences between the seasons where the rise in air temperature during the summer to raise the air to higher levels than in winter and spring. The seasonal variation was chosen because the period covered by the study is not long and one year only, so do not take the differences between the years in mind despite the possibility of giving us insights about the study. 


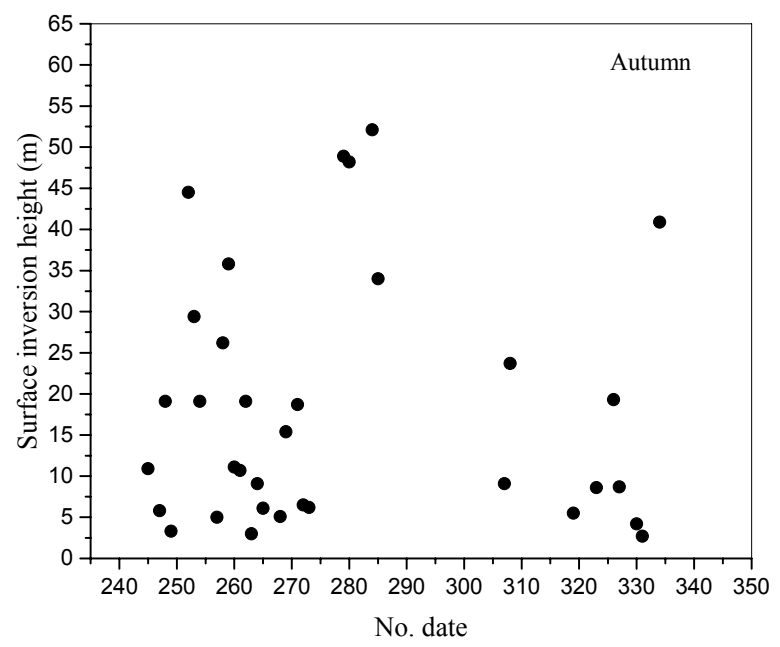

FIGURE 7. Daily variation in the height of the inversion during in the autumn

\section{Conclusions}

Due to different conditions for the formation of surface inversions, each season presents different characteristics and numbers of inversions. According to data obtained from Baghdad station the main remarkers are found:

- September records the highest relative frequencies of the surface heat inversions compared with the rest of the months Where it was $70 \%$ due to the different reasons that generates a $H_{\text {in }}$ from month to another. While increasing relative frequencies of the air temperature inversion during the quarterly summer and winter where it was $49 \%$ either during the spring and autumn less and this means frequencies $H_{\text {in }}$ less than in the transitional seasons because of the atmospheric conditions for these seasons do not constant. As well as for the relative frequencies.
- The highest rise of the surface heat inversion in the summer was $55.8 \mathrm{~m}$ and decrease the height in autumn and spring and then reach the lowest height in winter was $50.5 \mathrm{~m}$.

- Surface heat inversion (near earth's surface) occurs from about 2 to $50 \mathrm{~m}$ over Baghdad city.

\section{References}

Al-Jiboori, M.H. \& Jaber, S.H. (2018). The Study of Refractive-Index Structure Coefficient Behavior Derived from Two Weather Stations at Baghdad City. Al-Mustansiriyah Journal of Science, 29(4), 1-6.

Al-Jiboori, M.H. (2015). Atmospheric pollution. Baghdad: Al-Semaa Publisher Press.

Davidson, C. \& Spink, D. (2018). Alternate approaches for assessing impacts of oil sands development on air quality: a case study using the First Nation Community of Fort McKay. Journal of the Air and Waste Management Association, 68(4), 308-328.

Guédjé, F.K., Houéto, V.V.A. \& Houngninnou, E. (2017). Features of the low-level temperature inversions at Abidjan upper-air station (Ivory 
Coast). Journal of Materials of Environmental Sciences, 8(1), 264-272.

Heidorn, K.C. (1978). A chronology of important events in the history of air pollution meteorology to 1970. Bulletin of the American Meteorological Society, 59(12), 1589-1597.

Janhäll, S., Olofson, K.F.G., Andersson, P.U., Pettersson, J.B. \& Hallquist, M. (2006). Evolution of the urban aerosol during winter temperature inversion episodes. Atmospheric Environment, 40(28), 5355-5366.

Li, J., Chen, H., Li, Z., Wang, P., Cribb, M. \& Fan, X. (2015). Low-level temperature inversions and their effect on aerosol condensation nuclei concentrations under different largescale synoptic circulations. Advances in Atmospheric Sciences, 32(7), 898-908.

Malek, E., Davis, T., Martin, R.S. \& Silva, P.J. (2006). Meteorological and environmental aspects of one of the worst national air pollution episodes (January, 2004) in Logan, Cache Valley, Utah, USA. Atmospheric Research, 79(2), 108-122.

Milionis, A.E. \& Davies, T.D. (1992). A five-year climatology of elevated inversions at Hemsby (UK). International Journal of Climatology, 12(2), 205-215.

Serreze, M.C. \& Scnell, R.C. (1992). Low-level tropospheric temperature inversions in the Canadian Arctic. Atmosphere-Ocean, 30(4), 511-529.

Tyson, P.D., Preston-Whyte, R.A. \& Diab, R.D. (1976). Towards an inversion climatology of southern Africa: Part I, Surface inversions. South African Geographical Journal, 58(2), 151-163.

Yasmeen, Z. (2011). Inversion layer and its environmental impact over Karachi. Pakistan Journal of Meteorology, 7(4), 53-62.

Zhang, Q. \& Li, H. (2011). A study of the relationship between air pollutants and inversion in the ABL over the city of Lanzhou. Advances in Atmospheric Sciences, 28(4), 879-886. characteristics for Baghdad city. This inversion plays an important role in the study of concentrations of pollutants as well as its effect on spraying insecticides, which starts from a height of $2 \mathrm{~m}$ using the daily radiosonde data (midnight) of the period of 2013-2014 obtained from the Iraqi Meteorological Organization and Seismology. The frequencies average of the heat inversion was studied on a monthly and quarterly basis. It was clear from the study that surface heat inversion shows the highest monthly frequency average in the September; the lowest monthly frequency average in the March; highest seasonal frequency average in the summer and the lowest seasonal frequency average in the spring. As for the relative frequencies of the monthly and seasonal of the surface heat inversion was calculated, it was found that $49 \%$ occurs during the summer months also winter record the same relative frequencies of the surface heat inversion in the summer. It was done through this research calculated height of the surface heat inversion the results were heights inversion in winter.

\section{Authors' address:}

Shahad R. Al-Ghrybawi

Mustansiriyah University

College of Science

Atmospheric Sciences Department

Baghdad, Iraq

e-mail: Shahad2018_2019@yahoo.com

Monim H. Al-Jiboori

Mustansiriyah University

College of Science

Atmospheric Sciences Department

Baghdad, Iraq

e-mail: monim.atmsc@uomustansiriyah.edu.iq mhaljiboori@gmail.com

\section{Summary}

Study of surface heat inversions characteristics around Baghdad station. This work presents the surface heat inversions 